\title{
Facebook as a tool to Enhance Team Based Learning
}

\author{
Sami M. Alhomod \\ King Saud University, Riyadh-11321, \\ Saudi Arabia
}

\author{
Mohd Mudasir Shafi \\ King Saud University, Riyadh-11321, \\ Saudi Arabia
}

\begin{abstract}
A growing number of educators are using social networking sites (SNS) to communicate with their students. Facebook is one such example which is widely used by students and educators. Facebook has been recently used by many educational institutions but most of these have been related to provide the information to the general audience. There has not been much study done to propose Facebook as an educational tool in a classroom scenario. The aim of this paper is to propose the idea of using Facebook in team based learning (TBL) scenario. The paper demonstrates the use of Facebook at each level of TBL The paper shows how Facebook can be used by students and teacher to communicate with each other in a TBL system. The paper also explains teacher - team and teacher student communication via Facebook.
\end{abstract}

Keywords-Social Networking; Facebook; Team Based Learning; Communication.

\section{INTRODUCTION}

Team based learning (TBL) is based on the use of small groups in order to transform them into high performance teams to accomplish complex tasks. According to Fink [2], "Team based learning is a particular instructional strategy that is designed to (a) Support the development of high performance learning teams. (b) Provide opportunities' for these teams to engage in significant learning tasks". There have been a lot of studies that prove that team based learning and teaching have extremely effective to achieve wide range of goals. TBL promotes higher level reasoning, enhances content retention and learning and increases the social support in the classroom. TBL offers an opportunity for an average student to put more effort and enables teams to accomplish tasks which could not have been done by even the excellent students individually [2, 23].

Social networking site like Facebook has gained extreme popularity among the internet user over the past few years. These sites were intended for personal communication among individuals but now increasing number of organizations are using these sites to engage their stakeholders [13]. Facebook is one such site which has seen huge growth since its launch. Facebook offers a means of informal communication among its users [15]. A lot of studies have been conducted recently on

the use of Facebook in educational sector. These studies have established that Facebook can act as a tool of communication in the modern educational system. Today more and more educational institutions are experimenting with Facebook as a tool in education.

This paper examines the use of Facebook in a Team based learning system and points out the benefits of using Facebook in a TBL system. The paper is organized as follows; first we will provide a brief background of TBL and Facebook. Second, we will discuss the related work done in this regard. Next, we will describe how Facebook can assist TBL. And at last, we will provide a conclusion to the study.

\section{BACKGROUND}

\section{A .Team based learning}

The term "Team based learning" was first coined by during the 1970's. Team based learning(TBL) in education is a technique in which students work together in teams in order to learn things with better understanding. TBL transforms the traditional lecture based coursework into a more active selflearning and promotes teamwork. It allows students to achieve the levels of higher quality learning which can be hard to achieve when students are working individually [1]. TBL involves making small groups of students and using these groups as instructional strategy. TBL links each learning activity to the next activity in order to achieve deeper understanding among students and develop the teams of higher performance and understanding [2]. As an example, students can be asked to work in teams so that they can cover a more learning material without having to exert excessive pressure individually [3]. According to Michaelsen, Knight and Fink, 2002, there are two specific purposes of TBL:

1. Form Teams of high learning performance.

2. Participate and gain experience in tasks of educational importance.

Another important factor of TBL is group cohesiveness. As the students start working in teams, the group cohesiveness increases which results in higher level of efficiency and understanding among students. Once a student group is formed there are four stages of transforming it into a team. First the students interact with each other. Second, the students review the resources that are available to them. Third students receive a task and work towards its completion. And at last, performance of each individual member of group is evaluated. Once these stages are completed, the group has transformed into the team $[1,4]$.

One of the important benefits of team based learning is that it helps students with developing skills. Possessing excellent teamwork skills is one of the important factors for employers in the job market [5]. According to a survey conducted by Wall Street Journal, a teamwork skill is the second most important skill for the business graduates to possess [6]. TBL allows students to organize the problems and devise a solution for each problem accordingly.TBL also allows students to interact with each other on a daily basis and enables students to complete tasks within teams [4].

\section{B. FACEBOOK}


Facebook is one of the most popular Social networking Site today. It was created by Mark Zuckerberg in 2004 while he was a student at Harvard.[9,10] It was initially established to be used by Harvard students only and was extended to be used by other universities and school students in 2005. It was eventually opened to public in 2006. [11,12]. Facebook is currently one of the most sites visited on internet with more than 845 million monthly active users and is available in more than 70 languages.

Facebook is now used by a wide range of people at all levels of education and society as well as by large companies and universities.

Facebook provides its users with numerous ways to communicate with each other. As far as education field is concerned, Facebook can be used to:

a.) Create a group or network

b.) Build educational application for Facebook

c.) Integrate Facebook into current educational tools

d.) Develop a educational application with Facebook developer platform

e.) Share classroom and topic information with other users of the Facebook

According to Withall, (2005) "Facebook.com has become our social Bible for definitive information on our classmates crushes and high school peers we have not spoken to in whoknows-how long." Users use Facebook for daily chat or to discuss events in their life. People also use Facebook to share their thoughts as well as share information and URL's. People also use Facebook to comment on current events and also on some news items.

\section{RESEARCH OBJECTIVES}

The trend of using Facebook in a classroom is relatively new and little research has been done with reference to using it in classroom scenario. The aim of this study is to propose the use of Facebook in a team based learning scenario in a classroom. The study proposes following questions:

- How can Facebook be used by faculty in a TBL scenario?

- How can Facebook be used by students in a TBL Scenario?

- How can Facebook assist the Overall TBL Scenario?

\section{RELATED WORK}

Facebook has been subject of research among many scholars recently. Facebook has become a big part of student lives and that's the reason Facebook can have a major impact on education. Previous research has established that the university campuses have more than $90 \%$ usage rate of Facebook [14,15].

A study conducted by Nemec et.al demonstrated the use of Facebook applications as well as Facebook groups and chats to be used in courses. They concluded that Facebook applications and features can act as a supplement for the classroom program. Another study conducted by Ractham \&
Firpo, 2011, noted that Facebook allows students to gain informal learning through informal communication, get feedback on their thoughts and communicate without time ans space limit. They also noted the facility provided by Facebook to faculty which allows receiving feedback from students and constantly in touch with students.

Yu-ching Chen found that Facebook provided a common interaction environment which helps in problem solving and reasoning of the people which was reflected by the user satisfaction of Facebook and better academic performance of the students. The study also found that students found Facebook easy, convient, user friendly and simple for academic discussion. Another study by Madgea et.al proposed that Facebook can act as an important tool to aid students in settling in the classroom. They also proposed that Facebook can enhance their team work and organizational skills.

Mazer et.al conducted a study that found that students achieved higher level of motivation after they accessed the teacher's Facebook page them to create a positive atmosphere in the classroom. Laurie \& Paula, 2007 proposed the use of Facebook to promote online library services and events.

\section{PREPARING For THE FACEBOOK BASED TBL}

Before the Facebook is introduced in the class, some actions must be done by the teacher. The following things must be done before Facebook is integrated in a classroom:

A. Profile Page: A teacher must create a separate profile page that should only to be used for communication with his students.

B. Create class group page: A separate group page for each course should be created. On this page students can find their classmates and can communicate with them as well as with the teacher.

C. Create a team group: Each team must create a team group page for discussion with the other members of the team.

Once the Facebook environment for TBL is created a teacher can continue with the integration of Facebook into the courses.

\section{FACEBOOK BASED TEAM BASED LEARNING}

In TBL majority of class time is spent on activities so that students can learn to solve problems which they are likely to face in professional world. According to Michaelsen et al [20], there are three phases of any Team based Learning; preparation phase, application phase, assessment phase. We will discuss how Facebook can assist and enhance each of these three phases [21].

\section{A. Facebook based preparation phase}

In this phase students read the topics before they are discussed in the class. The main aim of this activity is to have a prior knowledge about the topic to be discussed in the class. This phase starts with individual preparation of the topic by each student of the group followed by discussing the topic in the group. The students first undergo the test individually followed by the same test in the group based on the topic. Both the tests are graded in class and announced. At the end teacher offers understanding of the concepts that were not 
understood by the student. This marks the end of the preparation phase.

Facebook can be of extreme importance in this phase. Firstly, students can communicate with teacher as well as among themselves to know about the topics to be discussed in the class before they actually enter the class over the classroom group page. The teacher can share the topic name on their classroom group page and all the students can have a prior knowledge about the topic. The teacher can also choose to give individual task to teams by sharing the topic on the team's group page. Once the topic is provided, the students in the group can discuss topic among each other both prior to coming in the class and during the class. Students in the group can communicate with each other by constantly sharing their thoughts on the question. This will enable students to work individually on the question and discuss it in the group. This will also help teacher to know about the students actively trying to solve the question and also about the students who are not contributing to solve the problem. This may help teachers to identify the weaker student in the group and possibly put more effort towards the weaker students of the group.

Once the tests are conducted individually as well as in teams, the teacher can declare results and provide solution to the question over the classroom group page or by posting the solution to the each team page. This will allow each student to cross examine their result and check the weakness in their answer. Once the results are announced the students can discuss the results among themselves. After the class is over the students can continue discussing the question and can continue discussing the topic even at their home. Using Facebook in this way enables to continue the classroom activity even after the class. The teacher can also participate in the discussion even after the school is over. The teacher can add to the topic at any time. The teacher can choose to inform few things about the topic so as to start the discussion and then gradually add to the topic. This will increase better reasoning among students and can help students to research more about the topic.

Facebook can also allow students an easier way to ask questions. If there is any point in the topic that a student don't understand or need more clarification, they can ask teacher or his team by raising the point on Facebook at any time.

\section{B. Facebook based Application phase}

In this phase students apply the knowledge of the course content they learned during the preparation phase to solve the problems, make predictions or create explanations for complex problems. Each group or team in this phase provides their responses to the problem in the class and the teacher evaluates the responses of each group to provide feedback to every group. At the end of this phase, students learn to work in team to provide solutions as well as form a strong bonding with the other students in the group.

Facebook can help in this phase by connecting students with each other as well as with teacher. The students and teacher can communicate with each other over the team specific group page. The constant contact between students and the teacher create cohesion among them which is important for student persistence [14]. Facebook can act as a constant medium for student groups and teacher interaction which is an important factor for the success of students [22].

The students in this phase can solve the problems and share their responses on their team page with other members of the team and with teacher. The teacher can post their responses on the Facebook page of the team. This will create a secret form of communication between teacher and the students. The teacher can choose to guide a particular group or student if they are not doing well as compared to the class. The student can post their arguments and question anytime on the team or classroom page and the teacher can choose to respond to these questions at any time. This will promote out of class learning and students and enable anytime / anywhere learning.

\section{Facebook based Assessment phase}

This is the Final phase of team based learning. In this phase teams are required to solve the problems based on the understanding of the course material [21]. This phase also allows students to use the previous studied material and incorporate it with the new material [1]. The responses from each team are evaluated by the teacher and the grades for each student and teams are decided.

Timely feedback is one of the fundamental principles of team based learning. It helps students in content retention and learning which in turn helps in student and team development [2]. Facebook can help in this notion of timely feedback. A teacher can provide feedback to student and teams on Facebook as soon as he is done with the assessment. For student it provides an opportunity to readily assess their performance as well as the performance of the team. A team can also share their comments regarding their results and performance.

Besides helping teacher and teams to accomplish their tasks, Facebook can also help in the formation of teams. A teacher can look at the profile page of students and can form teams based on students with similar interests. Facebook can also act as a debate starter. For example, a teacher can post some topic on classroom group page and ask teams about their thoughts about the topic. This can encourage out of class learning. Teams can discuss the topic over Facebook before the topic is actually discussed in the class. 


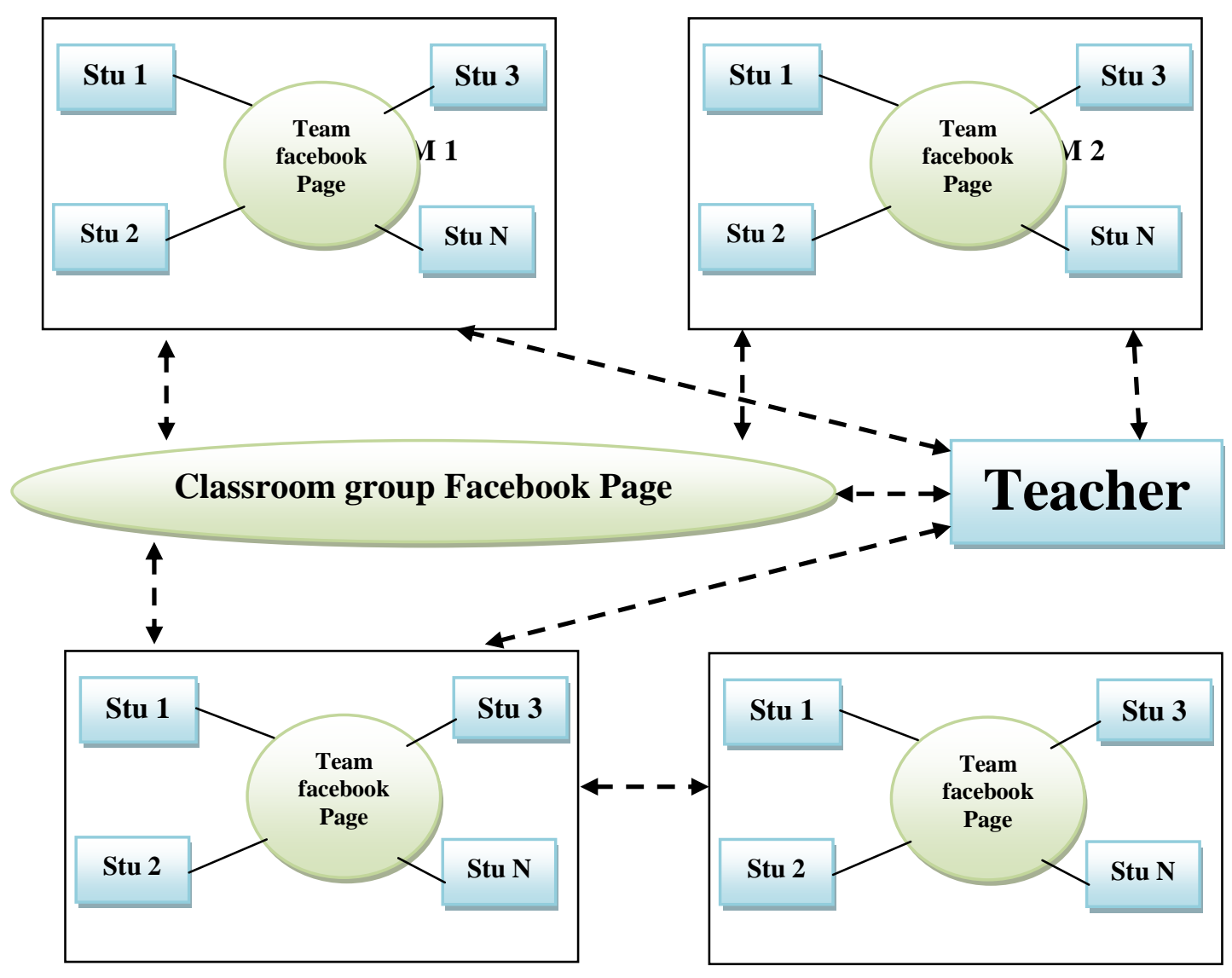

Fig. Facebook based TBL

Fig. above shows a general framework of using Facebook in a classroom structure. A team can communicate with each other using Facebook as well as communicate with teacher and other students in class via Facebook. Teams can set up their intra team Facebook page and discuss the problem assigned to the in team. Teams can remain in constant touch with each other even outside the class and can increase cohesiveness among the team which is important for the successful completion of the tasks. Students can also communicate individually with groups, teacher and other students via a common classroom Facebook page. Teachers can disseminate classroom information on the common Facebook page of the class. As far as teacher- team communication is concerned, this can be accomplished by forming a team specific page. Each team in the class can for a page which is connected only to their teacher. Teams can post their questions on this page and can receive answers from teacher on this page without the interference of out of team members. This can help to increase the teacher- team communication and can allow teacher to access the progress of each individual team. If the teacher has comments for a particular team, teacher can post his comments on the team specific page

without other teams and students getting to know about the comments. This can encourage the teams to work hard without going through embarrassment in front of the class.

\section{CONCLUSION AND FUTURE WORK}

It is established that TBL can enhance education in multiple ways. Recently Facebook has been used by many educational institutions as a tool to enable student achieve the desired outcomes. More and more educational organizations are using Facebook in one way or the other. Keeping this in mind, we tried to demonstrate how Facebook can further enhance the widely accepted mode of learning i.e. TBL. We tried to establish the high level of inter student, intra team interaction, student - teacher and team - teacher interaction via Facebook. This study demonstrated to use Facebook at each phase of TBL as well as tried to demonstrate the use of Facebook in a general classroom scenario. The paper tried to suggest the ways in which Facebook can be used in a TBL. As the use of Facebook in educational institutions grows, we recommend measuring the impact of Facebook in a TBL scenario. We also recommend measuring the impact of Facebook with other learning scenario as well as explore new ways of integrating Facebook into classroom structure. 


\section{REFERENCES}

[1] Michaelsen, L. K, Knight, A.B., \& Fink, L.D. (Ed.). (2002). "Team-Based Learning: A Transformative Use of Small Groups". Westport, CT: Praeger Publishers.

[2] Larry K. Michaelsen, Dean X. Parmelee, Kathryn K. McMahon, Ruth E. Levine, Diane M. Billings "Team-Based Learning for Health Professions Education: A Guide to Using Small Groups for Improving Learning"

[3] Lerner, L. D. (1995). "Making Student Groups Work". Journal of Management Education, 19(1), 123-125.

[4] Allison Brittney Goo, 2011"Team-based Learning and Social Loafing in Higher Education" Online Available: http://trace.tennessee.edu/utk chanhonoproj/1423/

[5] Chapman, K. J., Meuter, M., Toy, D., \& Wright, L. (2006). "Can’t We Pick our Own Groups? The Influence of Group Selection Method on Group Dynamics and Outcomes". Journal of Management Education, 30(4), 557-569.

[6] Alsop, R. (2004, September 22). "How to get hired", Wall Street Journal. p.R8

[7] Pavica Sheldon, "Student Favorite: Facebook and Motives for its Use"

[8] Taylor, Chris (June 27, 2011). "Social networking 'utopia' isn't coming". CNN. Retrieved December 14, 2011.

[9] A.Withall, R. (18 November 2005). Facing the facts about Facebook. The Villanovan.

[10] M.D. Roblyera, , , Michelle McDanielb, 1, , Marsena Webbc, 2, , James Hermand, 3, , James Vince Wittye "Findings on Facebook in higher education: A comparison of college faculty and student uses and perceptions of social networking sites" The Internet and Higher Education, 2010

[11] Lili Nemec, Marko Hölbl, Jernej Burkeljca, Tatjana Welzer "Facebook as a teaching tool"

[12] M. A. Urista, et al., "Explaining Why Young Adults Use MySpace andFacebook Through Uses and Gratifications Theory," HumanCommunication, vol. 12, pp. 215 - 229, 2008.

[13] Newsroom http://newsroom.fb.com

[14] Lee, M. J. W., and C. McLoughlin, "Harnessing the affordances of Web 2.0 and social software tools: can we finally make "student-centered" learning a reality?" presented at the World Conference on Educational Multimedia, Hypermedia and Telecommunications, Vienna, Austria, 2008.

[15] Leutner, D., and J. L. Plass, Measuring learning styles with questionnaires versus direct observation of preferential choice behaviour in authentic learning situations: the visualizer/verbalizer behavior observation Scale (VV-Bos). Computers in Human Behaviour, vol. 14, pp. 543-557, 1998

[16] Peter Ractham Daniel Firpo "Using Social Networking Technology to Enhance Learning in HigherEducation: A Case Study using Facebook "Proceedings of the 44th Hawaii International Conference on System Sciences -2011
[17] Yu-ching Chen "Learning Styles and Adopting Facebook Technology"

[18] Clare Madgea, Julia Meekb, Jane Wellens c and Tristram Hooleyd "Facebook, social integration and informal learning at university: 'It is more for socialising and talking to friends about work than for actually doing work'"Learning, Media and Technology Volume 34, Issue 2, 2009

[19] Joseph P. Mazer*, Richard E. Murphy \& Cheri J. Simonds "I'll See You On "Facebook": The Effects of Computer-Mediated Teacher SelfDisclosure on Student Motivation, Affective Learning, and Classroom Climate"Communication Education

[20] Michaelsen, L. K., Knight, A. B., \& Fink, L. D. (Eds.). (2004). "Teambased learning" Sterling, VA: Stylus.

[21] Haberyan, April, 2007 "Team-based learning in an Industrial/Organizational Psychology course" North American Journal of Psychology Volume: 9 Source Issue: 1

[22]Kuh G.D. (2002) "The National Survey of Student Engagement: Conceptual Framework andOverview of Psychometric Properties. Center for Postsecondary Research",Indiana university, Bloomington. Availableat:http://nsse.iub.edu/pdf/psychometric_framework_2002.pdf

[23] McKeachie, W., (1999). "Teaching tips: Strategies, Research, and Theory for College and University Teacher (10th ed)". New York: Houghton Mifflin.

[24] CHARNIGO Laurie, BARNETT-ELLIS Paula "Checking Out Facebook.com: The impact of a digital trend on academic libraries" Information technology and libraries,2007

\section{AUTHORS PROFILE}

Dr. Sami M. A. Al Homod is a faculty member in the department of Management Information Systems; College of Business Administration in King Saud University. He worked as the Dean of the eLearning and Distance Learning Deanship. He received his $\mathrm{PhD}$ in Information Technology from George Mason University; School of Information Technology and Engineering. He received his Master of Science in Information Systems from George Mason University; Information System and Software Engineering Department. He got his B.S. in Computer Information Systems from King Saud University; College of Computer and Information Sciences. He was A Board member of the Saudi Computer Society. He got a Distinguish Degree in Information Systems from George Mason University and Honor Degree from King Saud University. He is a member of many scientific and administrative committees and attended many conferences and scientific seminars.

Mohd Mudasir Shafi was born and raised in Srinagar, Kashmir, India. He has received his Master of Science in Computer Science from Jamia Hamdard (Hamdard University), New Delhi, India in the year 2009. He is currently working as a Researcher in Deanship of distance and Electronic Learning at King Saud University, Kingdom of Saudi Arabia. He has published many research papers in National and International journals. He has also actively attended many international conferences. His areas of interests are in E governance, Mobile governance, Network Privacy and security, Software Engineering, Social Media and E Learning. Apart from that he has previously worked as Quality Analyst and software engineer at various MNC's in India. 